\title{
Whitish haze, soapy globules: micro-analysis of degraded burmese paintings on zinc supports
}

\author{
Lynn Chua* ${ }^{*}$
}

\begin{abstract}
Two Burmese oil paintings on zinc supports depicting portraits of royal families, dated to the early 20th century by Saya Aye and Saya Mya, showed interesting corrosion, efflorescence and soapy globules for analytical investigation prior to conservation for exhibition. The features and colours on the two paintings, one of which was in worse condition than the other, were obscured by a whitish haze. Paint rupture and losses due to corrosion of the zinc support were apparent. Using a combination of 3D digital microscopy, FTIR microscopy and SEM-EDS, the degradation, as well as the paint materials and artists' techniques were analysed and discussed. Zinc soaps, oxalates, silicates, hydroxychlorides, carbonates, wax and mould characterized the haze. Interestingly, brown outlines in Aye's painting appeared unusually dark. Upon analysis, this degradation phenomenon was attributed to micro-sized greenish soap globules that have developed around copper/zinc (brass) particles, causing the brown outlines to lose their intended luminosity. The other painting by Mya, in which the same brown outline was applied, did not show such formation of globules. Detection of oxalates in the corrosion of zinc support and brown outlines are discussed. This study shows the importance in understanding the artists' materials and techniques, which have consequential effects to the degradation observed.
\end{abstract}

Keywords: Zinc support, Soap, Oxalate, Corrosion, Efflorescence

\section{Introduction}

The use of metal support for paintings, most commonly copper, has been favored by artists since ancient times for their reflected luminosity, durability and resistance to fluctuations in relative humidity [1]. However, not all paintings on metal support could survive without problems. Copper soaps forming at the oil-copper interface have been hypothesized to contribute to the delamination of paint [2] and corrosion of the metal substrate could also lead to paint blistering [3]. While much study was done on paintings on copper support [4-6], scientific study of paintings on zinc support was surprisingly limited. During this research, only one publication was identified on the conservation of painted zinc supports as part of the rebuilding of the Church of St David in Little

*Correspondence: Iynn_chua@nhb.gov.sg

Heritage Conservation Centre (National Heritage Board), Singapore, Singapore
Dewchurch, Hereford [7]. This study identified the main corrosion product as zinc sulphate, which can further dissolve in water to initiate corrosion. As a highly reactive metal in the periodic table, zinc tends to corrode much more quickly than other metals like copper, iron, tin, also used as metal supports in paintings. The zinc cations formed on the surface of zinc metal can potentially react with fatty acids released from the hydrolysis of oil binder, giving rise to zinc soaps at the paint-metal interface [8]. In paintings conservation, zinc soaps accumulating at the paint-ground interface can contribute to paint embrittlement and delamination problems [9-12].

This paper presents a case study that investigates the degradation on two Burmese oil paintings on zinc supports (c. 1918), "Royal Family Portrait with Musician" by Saya Aye (1872-1930) and "Royal Family Portrait" by Saya Mya (1893-1979), recently acquired into the collection of the National Gallery Singapore (Fig. 1a, b). Saya 


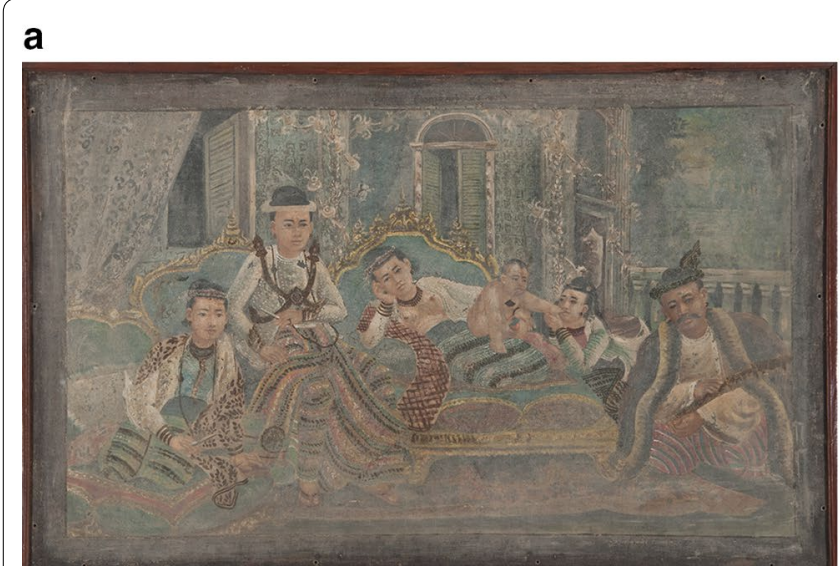

b

Fig. 1 "Royal Family Portrait with Musician" by Saya Aye (c. 1918) and "Royal Family Portrait" by Saya Mya (c. 1918)

Aye was a prolific court painter taught under Saya Chone (1866-1917), the originator of "Royal Family Portraits", and Saya Mya was a sculptor who sometimes painted under the tutelage of Aye [13]. It is worthwhile to highlight that this genre of "Royal Family Portraits" paintings in Burma (now Myanmar) started as a fashion from 1900 that lasted shortly for at least 2 decades and are considered a rare and important collection of Burmese art today [14].

These "Royal Family Portraits" paintings were kept as special ornaments in the living rooms of the rich, as an evidence of the family's high status and fine taste [15]. Portraying scenes of the royal families, most of the paintings' features and once bright colours were obscured by whitish haze, possibly corrosion or efflorescence. In some parts of the paintings, the extent of whitening made it difficult to appreciate the detail of the paintings' elements and the original motifs (for example, the clothing, carpet, and landscape in the background). In addition, the painting by Aye showed brown outlines that appeared darker and duller, suggesting an unusual chemical alteration. The use of zinc support could be influenced by Aye's practice in making religious paintings for the pagodas at Eindawya, also known to have deteriorated in condition [13]. It was possible that the zinc support was obtained from zinc sheet roofing common to traditional Burmese homes [16]. Selected for an upcoming exhibition, there were conservation concerns on the paint's stability and nature of the whitish haze, thereby initiating a scientific investigation of the degradation observed on the paintings. The two paintings investigated in this study belonged to a set of three, all of which were oil paintings on zinc support. The third painting, also executed by Saya Aye, did not show whitish haze and was not investigated in this study.
In this research, the scientific analysis aims to address two conservation questions: 1 . What constitutes the whitish haze and dark brown outlines observed on the paintings on zinc support? 2. Is the degradation stable for exhibition and how can we conserve the affected paintings? Additionally, this research provides an opportunity to study the materials and technique used in creating Burmese Royal Family portraits, which have not been analysed before nor recorded elsewhere. This paper also hopes to contribute to the scarce scientific information of oil paintings on zinc support.

\section{Results and discussion}

\section{Condition assessment}

The back of the zinc support in Saya Aye's painting was inscribed with a trademark stamp named "Rangoon", the formal name for the present Yangon, capital of Myanmar (Fig. 2a). With UVF lighting, a date " $3 / 2 / 18$ " was revealed at the bottom of Saya Aye's painting, which in the 20th century British-ruled Burma (1824-1948) would be regarded as 3rd Feb 1918 (Fig. 2bii). This date had gone unnoticed buried under the white efflorescence when viewed in normal visible light (Fig. 2bi). Mya's painting, however, did not show a date nor stamp.

Upon closer examination of the paintings in UVF light, the shading within the figures in Mya's painting showed peculiar brushstrokes parallel to the figures' silhouette. An example of these brush strokes could be seen in the baby's silhouette in Mya's painting that were otherwise not apparent in Aye's painting (Fig. 3). These parallel brown brush strokes in Mya's figures appear discordant, as if they were painted intentionally over a fluorescing white paint.

To clarify our understanding, paint samples from the brushstrokes in Mya's painting were analysed. 


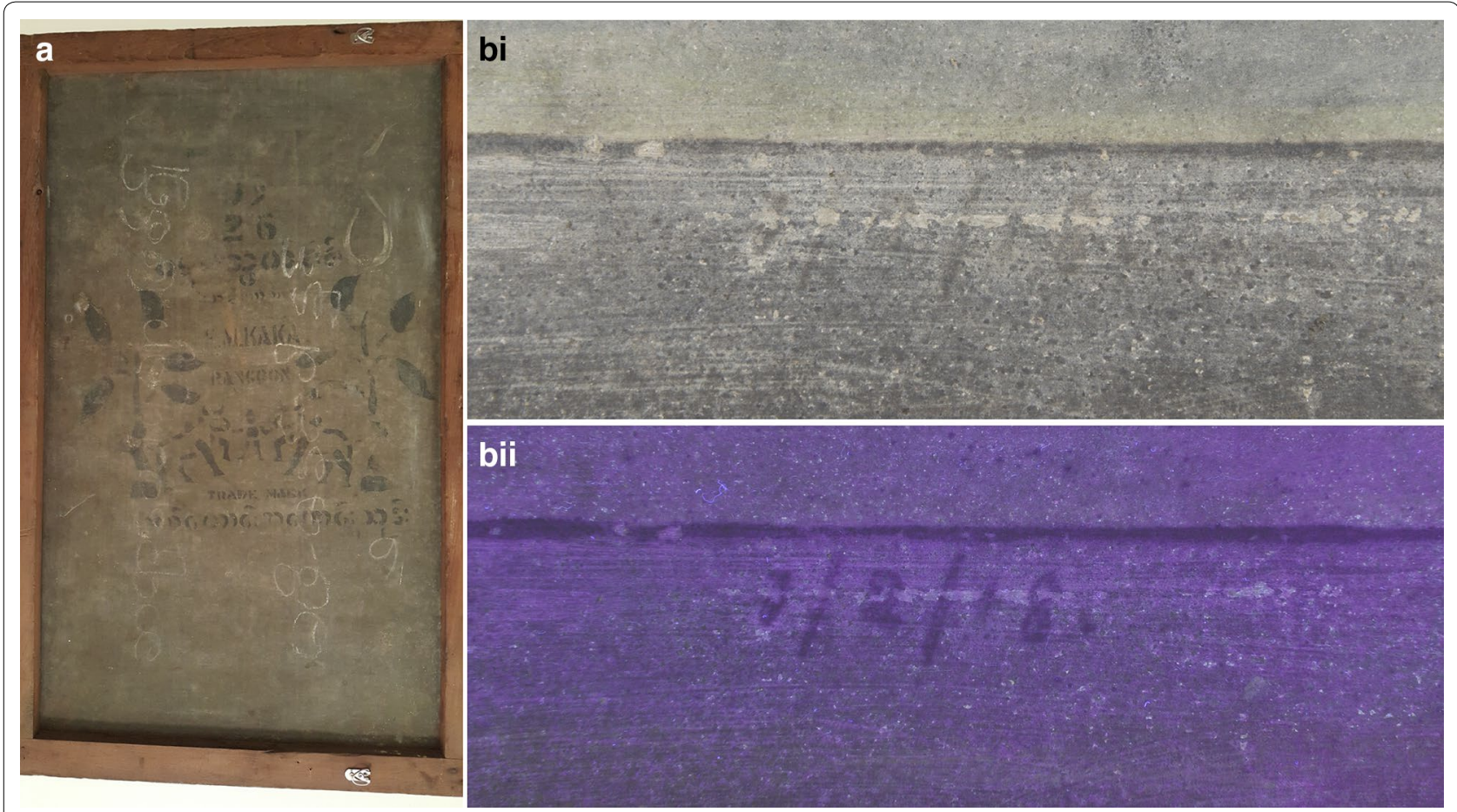

Fig. 2 Images taken during an examination of Saya Aye's painting: a trademark stamp on back of zinc support; date on bottom right corner in bi visible light and bii UVF light

a

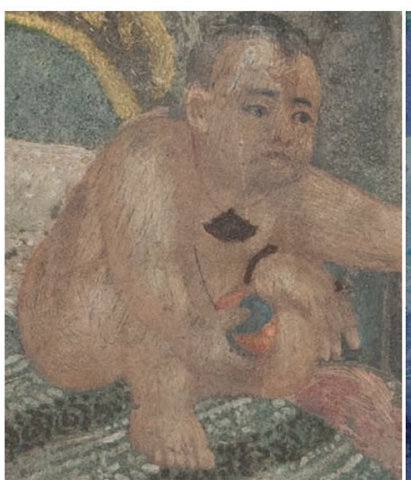

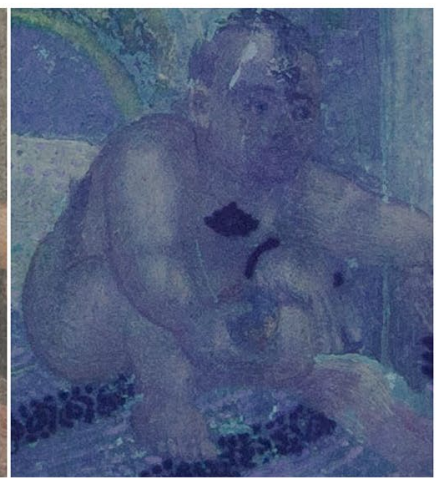

b

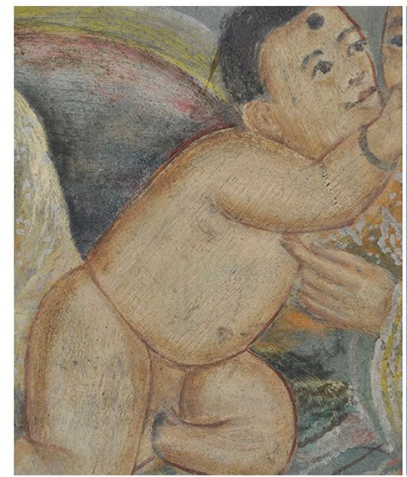

Fig. 3 Close-up images of baby figure in visible and UVF light: a Aye's painting, b Mya's painting

SEM-EDS revealed that the bottom fluorescing layer consisted lead $(\mathrm{Pb})$, likely lead white, whereas the upper non-fluorescing layer was composed of significant amounts of titanium ( $\mathrm{Ti}$ ) and iron (Fe), likely a mixture of titanium white and iron oxides to give the brown colour. The presence of titanium white, a white pigment commonly used in the 20th century, was unexpected since the painting would have been executed earlier around 1918. With Raman microscopy, the titanium white polymorph was verified as rutile, which is known to be commercially available after 1941, years after anatase (the other common polymorph of titanium white) was first produced in 1916 [17, 18]. Having found the analysis of titanium white (rutile) in the upper non-fluorescing layers opens up the possibility that later retouching had been done on Mya's painting. 
Table 1 Summary results of paint pigments with FTIR and SEM-EDS

\begin{tabular}{|c|c|c|c|}
\hline & SEM-EDS & FTIR & Result \\
\hline \multicolumn{4}{|l|}{ Saya Aye (sampling location) } \\
\hline White (curtain) & $\mathrm{Pb}(\mathrm{Al}, \mathrm{Cu}, \mathrm{Zn})$ & Lead white & Lead white \\
\hline Red (shirt of daughter) & $\mathbf{C}^{*}, \mathbf{P b}, \mathrm{Al}, \mathrm{Si}, \mathrm{P}, \mathrm{Zn}, \mathrm{Ca}(\mathrm{Mg}, \mathrm{K}, \mathrm{Fe}, \mathrm{Cu})$ & Lead white & Lead white + organic dye? \\
\hline Orange (ball on baby's hand) & $\begin{array}{l}\mathrm{C}^{*}, \mathrm{~Pb}, \mathrm{Zn}(\mathrm{Al}, \mathrm{Mg}, \mathrm{Si}, \mathrm{P}, \mathrm{K}, \mathrm{Ca}, \mathrm{Ba}, \mathrm{Cr}, \\
\quad \mathrm{Fe}, \mathrm{Cu})\end{array}$ & Organic dye, possibly madder & Organic dye, possibly madder \\
\hline Yellow (design on armchair) & $\mathrm{Pb}(\mathrm{Al}, \mathrm{Ca}, \mathrm{Cr}, \mathrm{Cu}, \mathrm{Zn})$ & $\begin{array}{l}\text { Lead chromate, barium sulphate, } \\
\text { lead white, zinc soaps }\end{array}$ & Chrome yellow, lead white \\
\hline Blue (ball on baby's hand) & $\mathbf{P b}, \mathrm{Zn}, \mathrm{Ca}(\mathrm{Al}, \mathrm{Si}, \mathrm{P}, \mathrm{K}, \mathrm{Ba}, \mathrm{Fe}, \mathrm{Cu})$ & Prussian blue, lead white & Prussian blue, lead white \\
\hline Green (sleeve of daughter) & $\mathbf{P b}(\mathrm{Mg}, \mathrm{Al}, \mathrm{Si}, \mathrm{P}, \mathrm{K}, \mathrm{Ca}, \mathrm{Ba}, \mathrm{Cr}, \mathrm{Fe}, \mathrm{Zn})$ & Prussian blue, lead white & $\begin{array}{l}\text { Prussian blue, chrome yellow, lead } \\
\text { white }\end{array}$ \\
\hline $\begin{array}{l}\text { Silver dots (design on upper } \\
\text { clothing) }\end{array}$ & Al & - & Aluminum \\
\hline \multicolumn{4}{|l|}{ Saya Mya (sampling locations) } \\
\hline White (scarf) & $\mathrm{Pb}(\mathrm{Al}, \mathrm{Cu})$ & Lead white & Lead white \\
\hline Red (skirt) & $\mathbf{P b}, \mathbf{H g}(\mathrm{Zn}, \mathrm{Cu}, \mathrm{Ca}, \mathrm{Al})$ & Lead white & Vermilion, lead white \\
\hline Orange (at center of couch) & $\mathbf{C}^{*}, \mathbf{P b}, \mathrm{Ba}, \mathrm{S}(\mathrm{Mg}, \mathrm{Al}, \mathrm{Ca}, \mathrm{Cu}, \mathrm{Zn})$ & Lead white, barium sulphate & $\begin{array}{l}\text { Lead white, barium sulphate, organic } \\
\text { dye? }\end{array}$ \\
\hline Yellow (curves on armchair) & $\mathrm{Pb}, \mathrm{Cr}, \mathrm{Ca}(\mathrm{Mg}, \mathrm{Al}, \mathrm{Si}, \mathrm{Cu}, \mathrm{Zn})$ & Lead chromate, lead white & Chrome yellow \\
\hline Blue (shirt) & $\mathbf{P b}(\mathrm{Al}, \mathrm{Si}, \mathrm{P}, \mathrm{Fe}, \mathrm{Cu}, \mathrm{Zn})$ & Prussian blue, lead white & Prussian blue \\
\hline Green (leaves on trees at back) & $\mathbf{P b}, \mathrm{Ca}, \mathrm{Cr}(\mathrm{Al}, \mathrm{Si}, \mathrm{P}, \mathrm{K}, \mathrm{Ba}, \mathrm{Fe}, \mathrm{Cu}, \mathrm{Zn})$ & $\begin{array}{l}\text { Prussian blue, lead white, chrome } \\
\text { yellow }\end{array}$ & Prussian blue and chrome yellow \\
\hline Silver dots (on scarf) & Al & - & Aluminum \\
\hline
\end{tabular}

Relative amounts in major, minor and (traces)

$C^{*}$ refers to carbon from the sample or the carbon adhesive tabs used to mount the sample

\section{Paint analysis}

Traditional paintings of "Royal Family Portraits" in Chone's times (1900s) were created using opaque watercolors on thin cotton [13]. Conversely in this study, the oil paintings on zinc supports executed by Aye and Mya in a later period (c. 1918) showed a deviation from traditional materials used. From our findings, Aye was considered one of the first artists to combine traditional and western techniques and was known to have used "easily applicable imported paints" [19]. Table 1 lists the results of the pigments identified with SEM-EDS and FTIR spectroscopy. The pigments identified were mainly inorganic, namely lead white, chrome yellow, and Prussian blue. It is interesting that the silvery dots used to render luminosity to the clothing were identified as aluminum, and not metallic silver as had expected.

In general, it was difficult to ascertain if a ground exists between the zinc support and painted layers, since whitish zinc corrosion concealed almost all areas with paint losses. In some areas of paint loss unaffected by the haze (Aye's painting), a cream-colored layer beneath the paint that might be a ground layer was analysed as barium sulphate and zinc soaps with FTIR spectroscopy and SEMEDS. Mineral wax was also detected in this layer.

In both paintings, lead white was identified as the primary and only white colour mixed into other coloured paints. The SEM-EDS results of most micro-samples from paint layers showed small to trace amounts of zinc in both paintings (Table 1). The source of zinc in the sampled paints is likely due to the associated degradation products from the zinc support. Another possible source could be the presence of zinc stearate additive, introduced as dispersion agents in commercial oil paints in the 1920s [20]. However, the likelihood of zinc stearate additive in the oil paint was low, since the paintings were executed earlier, dated to 1918 and after. Moreover, the FTIR spectra of the paint samples showed broad bands of zinc or lead carboxylate soaps, rather than zinc stearates which would show sharper bands.

\section{Characterisation of white haze}

The painting by Saya Aye was more severely affected by whitish haze than the painting by Saya Mya. The most intense corrosion in both paintings was observed in the blacks, especially along the border. The low atomic size of carbon black could explain for the paint's tendency to rupture with corrosion. Under the light microscope, the haze appeared differently, as whitish crust surrounding ruptured paint islands (Fig. 4a), corrosion of the zinc support (Fig. 4b), thin web-like strands over the paint surface (Fig. 4c), or as white efflorescence enveloping the surface of the paint (Fig. 4d). With SEM, some of the 

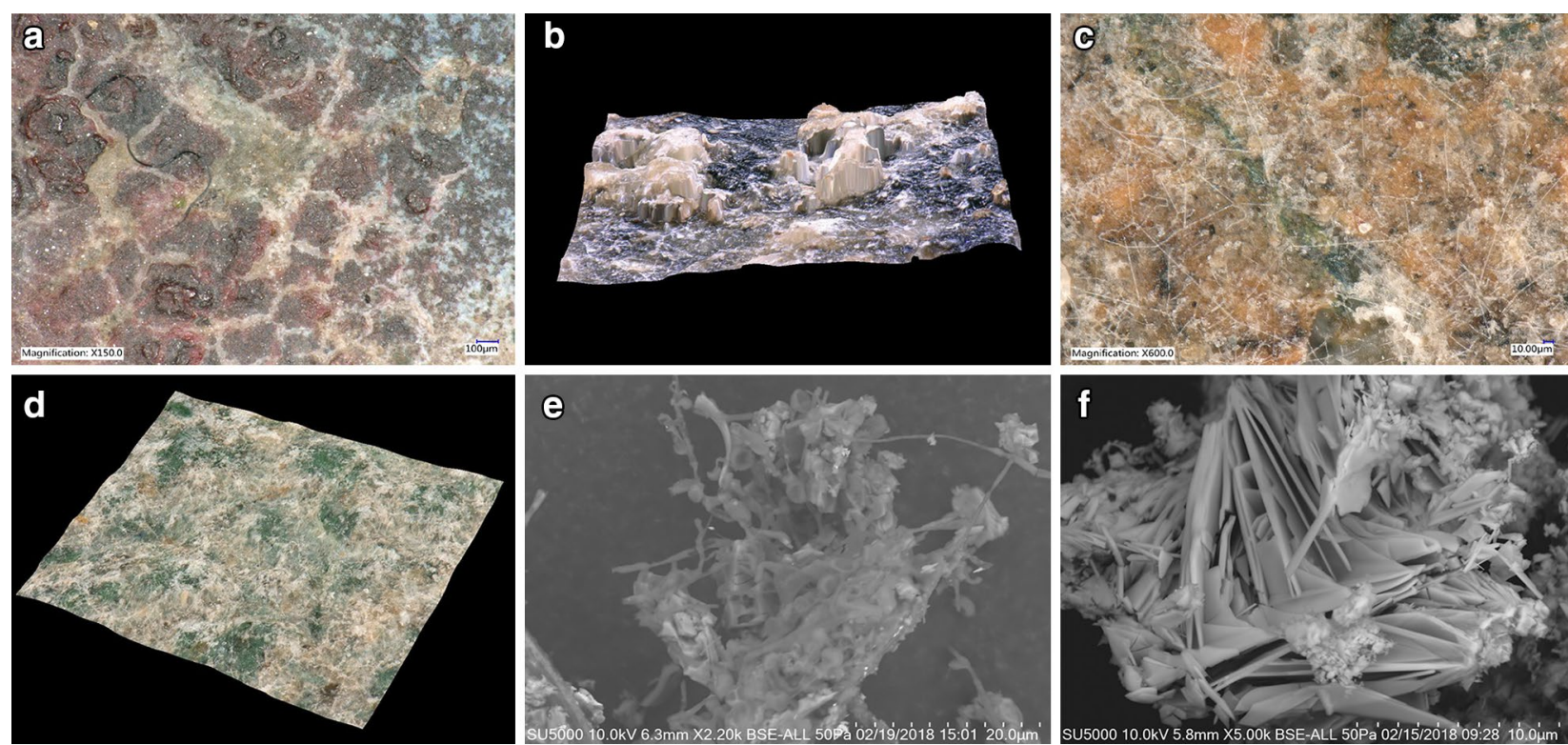

Fig. 4 Examples of haze on both paintings. Digital microscope images: a Mya_cushion seat at bottom right, b Mya—an area of paint loss along black border, $\mathbf{c}$ Aye — coloured pants of the patriarch, $\mathbf{d}$ Aye—cushion seat at bottom left. SEM images: e Aye—sample of haze from black background in the window on left and $\mathbf{f}$ Aye — sample of haze from a paint loss at black border

haze samples showed hyphae and spores characteristic of mould (Fig. 4e) and crystalline formation of zinc corrosion products (Fig. 4f).

For each painting, micro-amounts of the haze were sampled from different locations and layers at which the haze occurred. The areas selected included the haze on a coloured paint surface and its surroundings, haze on the black paint at border, corrosion on zinc in areas of paint loss at the black border, and corrosion of zinc at the back of the zinc support. Table 2 lists the location of haze sampled and the results identified by FTIR microscopy. The haze identified on the paint layers were mainly zinc carboxylate and wax, whereas the hazes from the zinc support were more varied, composing of zinc oxalates, hydrozincite, simonkolleite, zinc stearate, zinc carboxylate and wax. The back of the zinc support was mainly identified as zinc oxalate. No pattern could be found that relates an appearance of haze to a specific chemical compound.

Some of the corresponding FTIR spectra of the haze were shown in Fig. 5 to represent the nature of zincderived degradation products on the paintings. Corrosion products of zinc, namely simonkolleite (M5: 3490, 3455, 1043, 904, $721 \mathrm{~cm}^{-1}$ ) and hydrozincite (M4: 1504,1393 and $831 \mathrm{~cm}^{-1}$ ), were identified in areas of paint loss at the black border. The marker bands at $1629,1365,1319 \mathrm{~cm}^{-1}$, with $827 \mathrm{~cm}^{-1}$ and $781 \mathrm{~cm}^{-1}$ were attributed to zinc or calcium oxalate (A6). These oxalates at the back of the zinc support can serve as a water-insoluble stable crust that inhibits further corrosion [21]. A strong band at $3689 \mathrm{~cm}^{-1}$ with a weak band at $3644 \mathrm{~cm}^{-1}$ (A3) indicated the presence of chrysotile (a type of asbestos), probably an impurity transferred from building or roofing materials used for the zinc support.

Zinc soaps were either identified as zinc stearate or palmitate characterised by the well-defined bands at 1539 , $1462,1396 \mathrm{~cm}^{-1}$ (A1, M3) [22], or as a mixture of zinc carboxylate characterized by a broad band at 1590-1630 and $1394 \mathrm{~cm}^{-1}$ (A2, A4, A5, M2). The latter zinc carboxylate spectrum also showed the presence of wax, characterized by a splitting doublet at $719 / 729 \mathrm{~cm}^{-1}$ and $1461 / 1471 \mathrm{~cm}^{-1}$ (M2). The doublet at $1461 / 1471 \mathrm{~cm}^{-1}$ coalesced into a singlet at $1461-1464 \mathrm{~cm}^{-1}$ for some samples (A2, A4, A5), probably due to the overlapping vibrations of zinc carboxylates. So far, all the FTIR spectra that detected wax did not show $\mathrm{C}=\mathrm{O}$ and $\mathrm{C}-\mathrm{O}$ vibrations at $1730,1310-1110 \mathrm{~cm}^{-1}$, suggesting the presence of a mineral wax such as paraffin or microcrystalline wax. In the FTIR spectrum of samples A2, A4, A5 and M2 containing zinc carboxylates, other bands present at 1436, 1327, 1295, $1257 \mathrm{~cm}^{-1}$ were not attributed. It was thought that these vibrations were due to shorter organic acids associated with the degradation of wax additives. Since wax was detected on zinc and below the paint surface, wax was probably applied as a hydrophobic coating to prepare the zinc supports before paint application. The wax detected on the paint surface could be due to 
Table 2 FTIR microscopy results of white haze samples

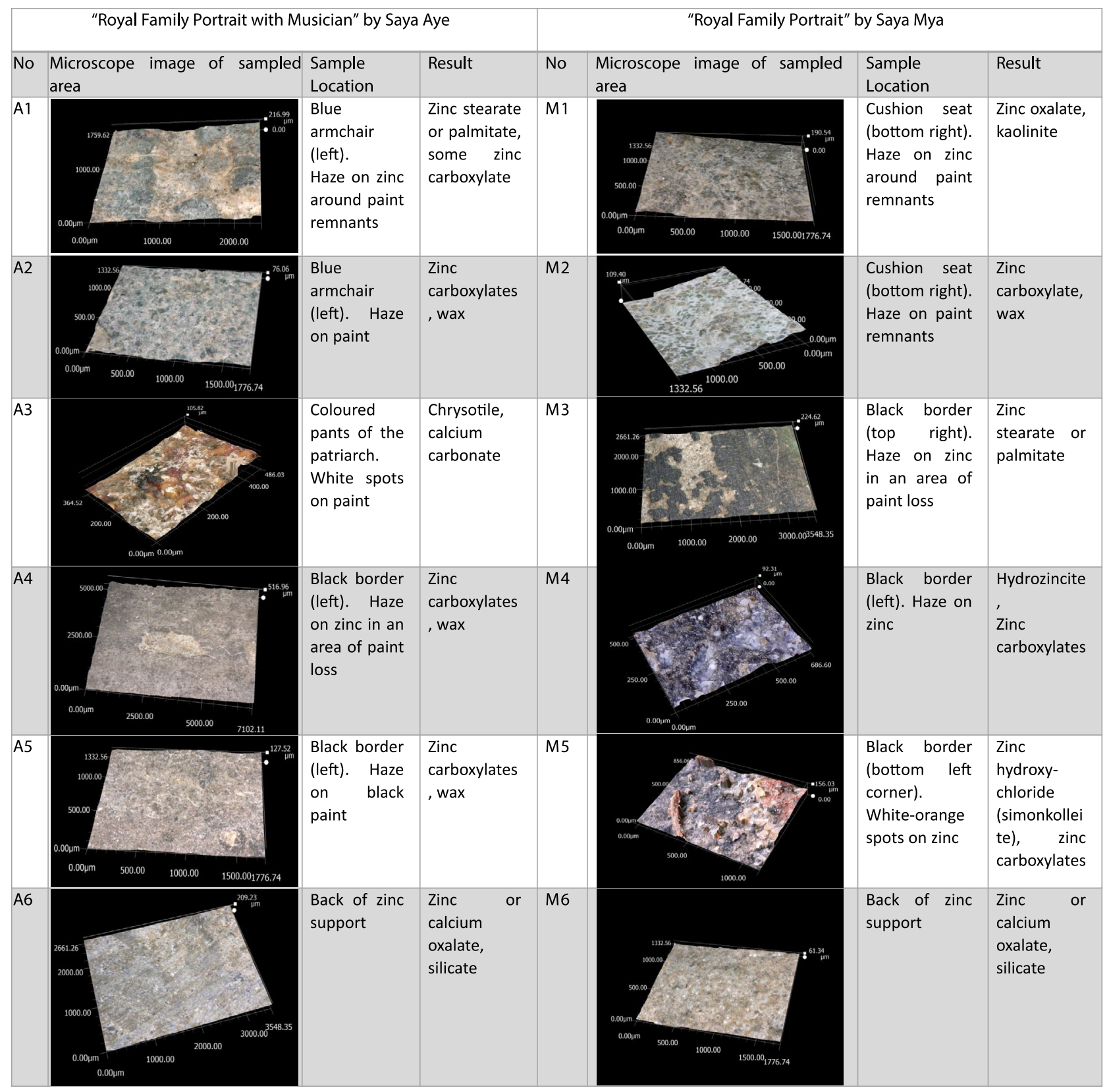

migration from the preparation layer or that a wax varnish was added to protect the painting.

\section{Characterisation of brown outlines}

Brown outline is a unique style seen in both paintings, used to highlight the metallic features of the painting, such as the armor on the patriarch, jewellery, scarfs with metallic designs, and tracing of border of the family portrait. As seen in Fig. 6ai, bi, the brown outlines in the painting by Saya Aye appeared much duller and darker than Mya's, suggesting a chemical alteration had occurred. Interestingly, a closer look of the dark brown outlines at higher magnifications revealed tiny greenish globules protruding from the surface of the paint (Fig. 6aii). These globules were not apparent in the other painting by Saya Mya (Fig. 6bii).

The green globules occurred randomly in varied sizes along the brown outlines, ranging from 20 to $100 \mu \mathrm{m}$ in height (Fig. 7a). With EDS mapping, the cross-section of a green globule revealed the presence of copper 


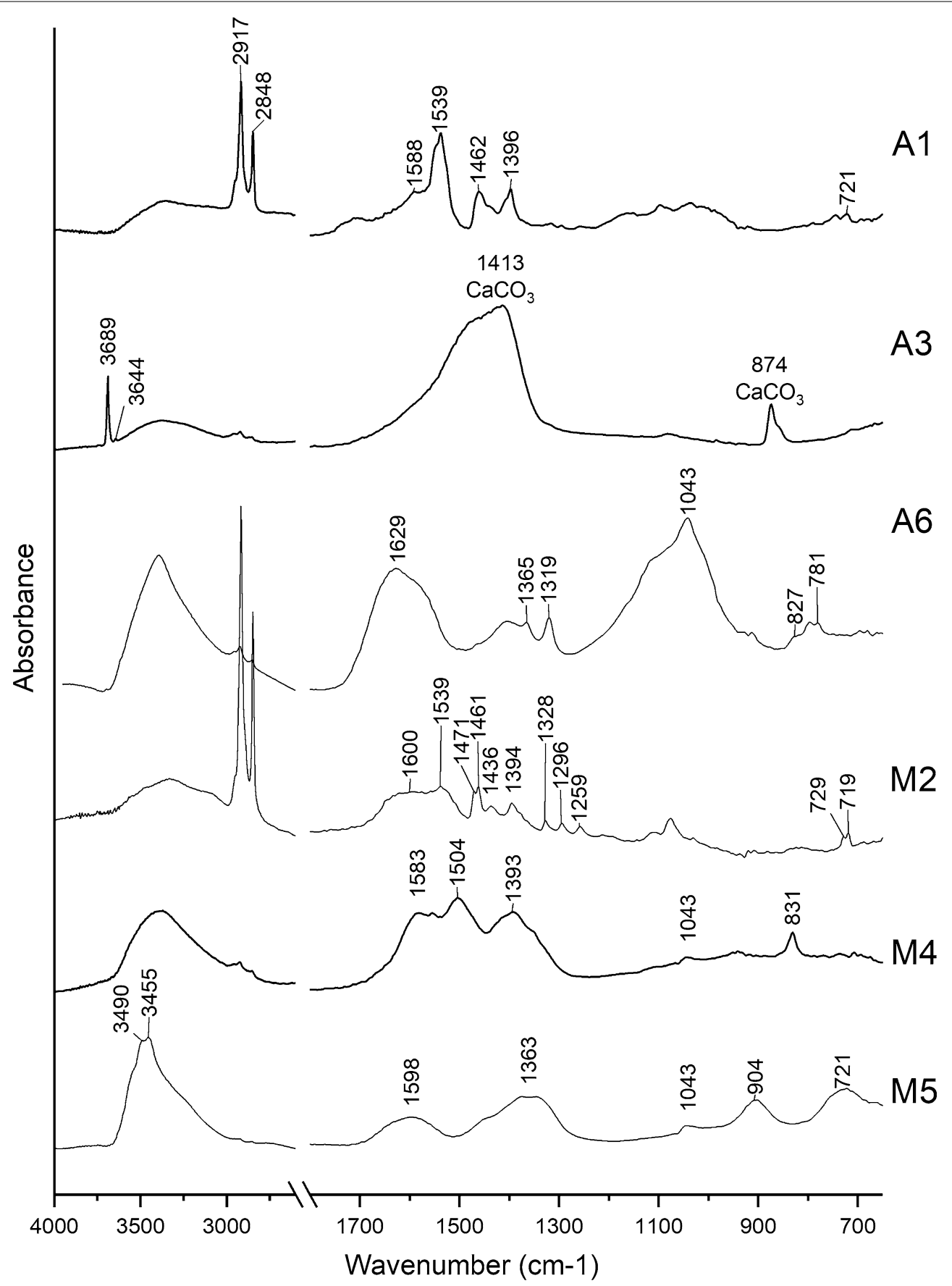

Fig. 5 FTIR spectra of selected samples in Table 2. Marker peaks were labelled

$(\mathrm{Cu})$ and zinc $(\mathrm{Zn})$ at the inner core in a ratio similar to brass (Fig. 7b). The FTIR analysis of the green globule identified a mixture of copper and zinc stearates or palmitate (Fig. 8a), such that the bands at 1538, 1464 and $1401 \mathrm{~cm}^{-1}$ were attributed to zinc stearate or palmitate, and $1588 \mathrm{~cm}^{-1}$ was attributed to copper stearate or palmitate $[23,24]$. Aluminum stearate was unlikely present as EDS spectrum of the green globule showed mainly $\mathrm{Cu}$ and $\mathrm{Zn}$, and a band around $3650 \mathrm{~cm}^{-1}$ for $\mathrm{Al}$ stearate was absent in the FTIR spectrum. The well-defined carboxylate bands in the FTIR spectra (Figs. 5A1, 8a) could be derived from additives (e.g. stearin or glyceryl tristearate, beeswax) incorporated into mineral wax, a common formulation of wax mixture recipes in the 19th century 
ai

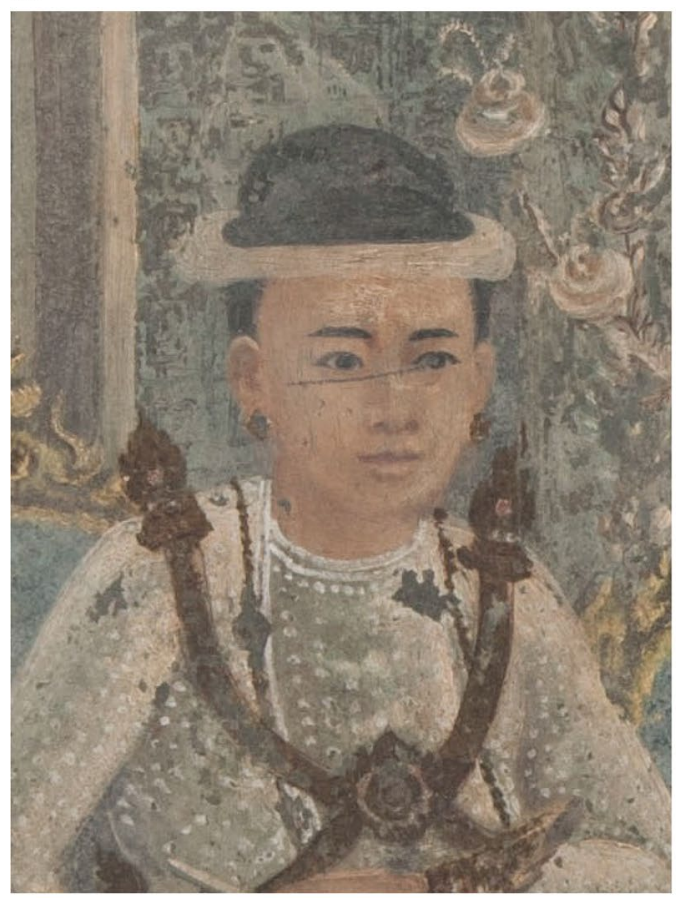

aii

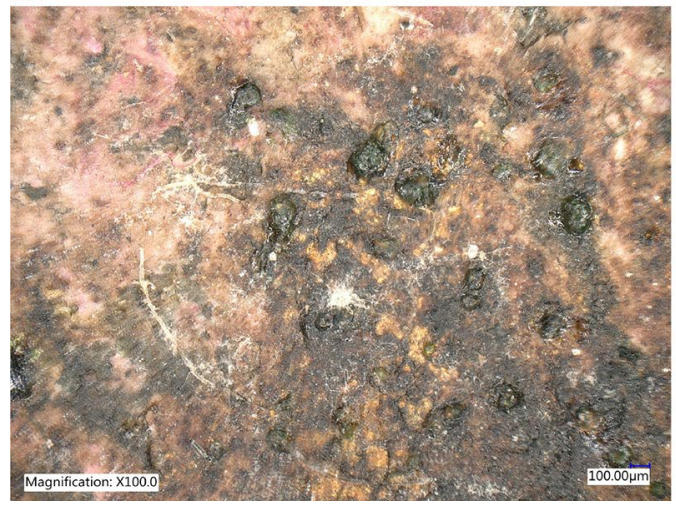

bi

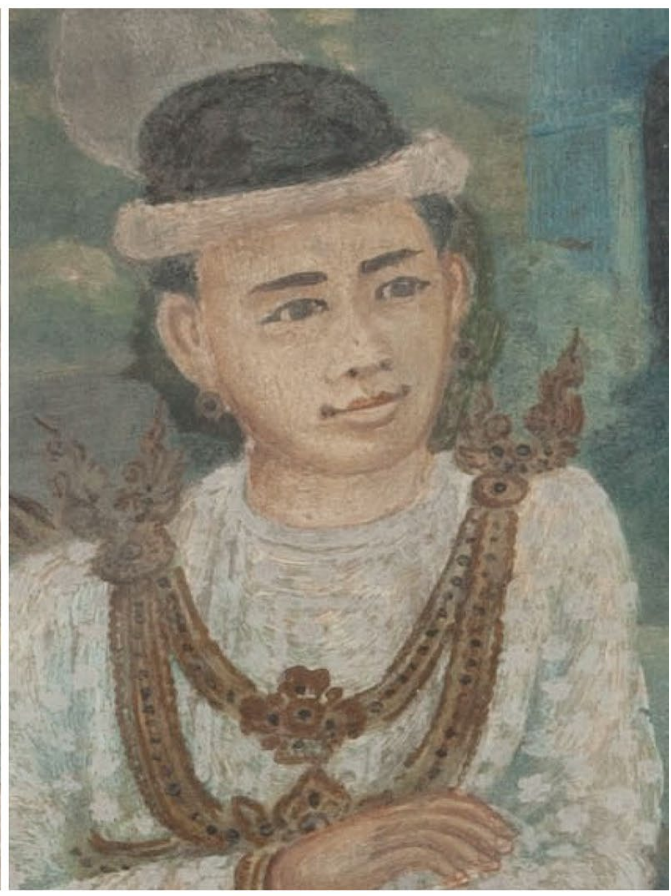

bii

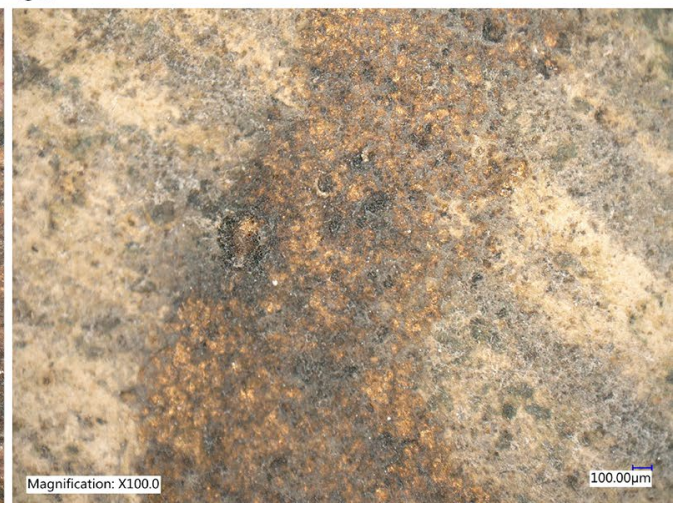

Fig. 6 Brown outline of the armor worn on the patriarch on paintings of ai Saya Aye and bi Saya Mya, aii, bii with their corresponding microscopic images at $\times 100$ magnifications

[25]. It might also be possible that commercial oil paint containing zinc stearate additive was used [20], which if true, would imply that brass paint for the brown outlines was applied at a later date after 1918. The crystalline and ordered formation of stearates around brass metal core particles may also contribute for the narrower bands in the FTIR spectrum.

Brass paint was added with the intention to create lustre in the brown outlines. Unfortunately, the combination of brass particles with the oil binder or wax additive had inadvertently caused the formation of soapy globules $(\mathrm{Cu} / \mathrm{Zn}$ stearates or palmitates) and a loss of lustre, reversing the artist's original intention. It is interesting to note a similar case of faded shine in 19th century Swiss oil paintings, in which brass powder grounded from foil led to the formation of copper and zinc carboxylate agglomerates [26].

On the contrary, the light brown outline in the painting by Saya Mya appeared more luminous and no green globule was detected. The corresponding EDS spectrum showed major amounts of $\mathrm{Cu}$ with small amounts of $\mathrm{Zn}$, indicating that brass was likely used. In this case, the FTIR spectrum of the light brown sample in Mya's painting showed broad bands at 1622 and $1409 \mathrm{~cm}^{-1}$ 


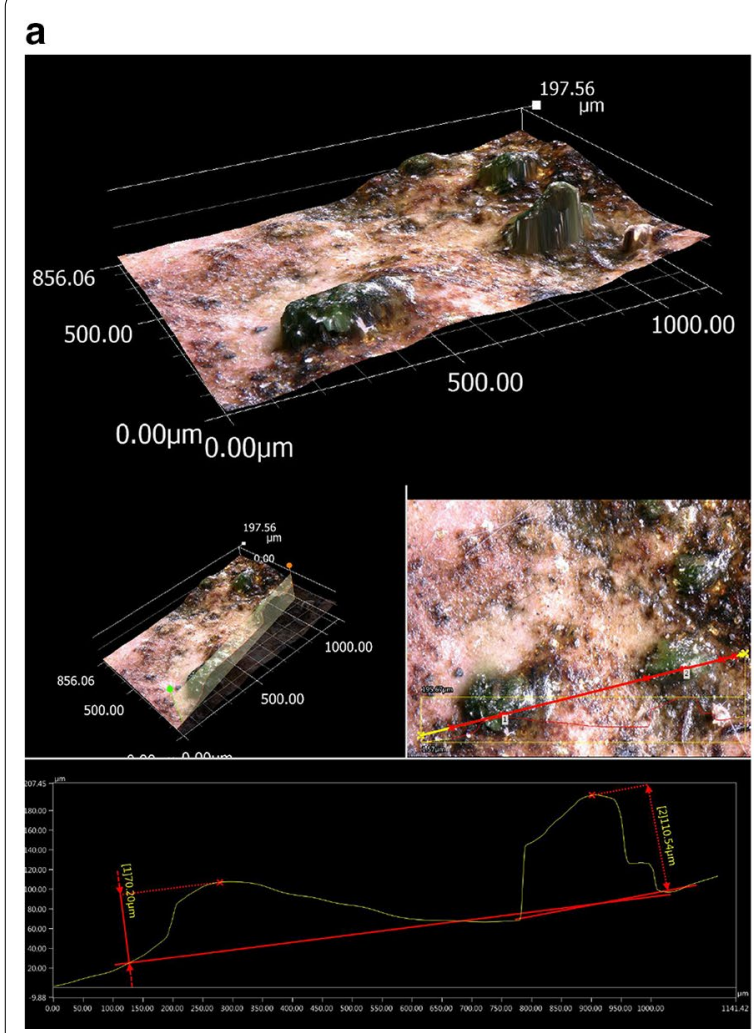

b

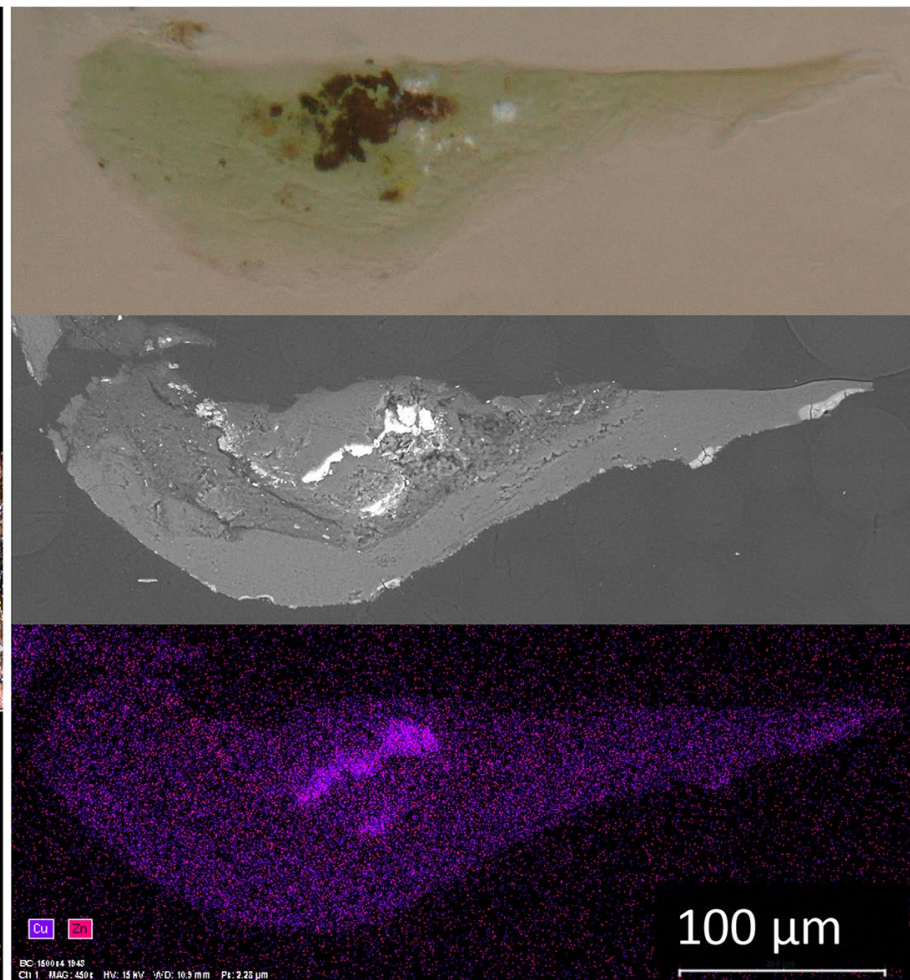

Fig. 7 a 3D surface topography of green globules in the brown outlines and its corresponding side profile, $\mathbf{b}$ polished cross-section of a green globule (top: visible image; Middle: SEM image; bottom: EDS mapping image of Cu and Zn)

attributed to mixtures of zinc carboxylates (Fig. 8c). The absence of green globules suggests that the brass paint applied by Mya was different from Aye's, likely without stearate or palmitate additive.

The brown matrix surrounding the green globules in Aye's painting was identified as copper and calcium oxalates, as shown by the marker peaks at 1637,1363 , 1317 and $819 \mathrm{~cm}^{-1}$ in the FTIR spectrum (Fig. 8b) [27]. Similarly, the dark brown matrix in Mya's painting also showed metal oxalates, in which this micro-sample showed more of calcium oxalates, characterized by 1640 , 1367, 1320 and $782 \mathrm{~cm}^{-1}$ in the FTIR spectrum (Fig. 8d). The results suggest that metal oxalates contributed to the darkening of the brown outlines. Other than the brown outlines, metal oxalates were also detected at the front and back of the zinc support in both paintings. The origin of the oxalates and the exact mechanism from which they were formed remains unclear [27] and could be due to biological activity of micro-organisms from organic substances [28, 29], previous conservation treatments that used oxalic acid [30] or oxidative degradation of organic binder and resins in the paint layer [31, 32]. In the case of Aye and Mya's paintings, as the occurrence of metal oxalates in the brown outlines was associated with metal soaps, it was more appropriate to trace the origin of oxalates to the oxidative degradation of organic binder. However, the origin of zinc oxalates at the back of the zinc supports could not be ascertained, since no organic coating, debris or micro-organism at the back of the zinc support was found. Recent study showing oxalic acid as the most abundant dicarboxylic acid in atmospheric aerosols could be postulated as the reason for zinc oxalates at the back of the zinc support [33].

\section{Conservation concerns}

The analysis results of the Burmese paintings enhanced our understanding of the degradation observed at the paint-metal interface for conservation. While the haze is undesirable, especially for the painting by Aye, the removal of the haze remains questionable. The paint layers were very thin and, in some areas, the corrosion had caused the paint to rupture into islands. In such a condition, any mechanical removal of the whitish haze would be highly disruptive for the remaining original paint. Despite the fact that zinc soaps would weaken the paint and lead to delamination problems, the paint remnants on these paintings were surprisingly well-attached to the zinc support and did not exhibit active flaking. It was 


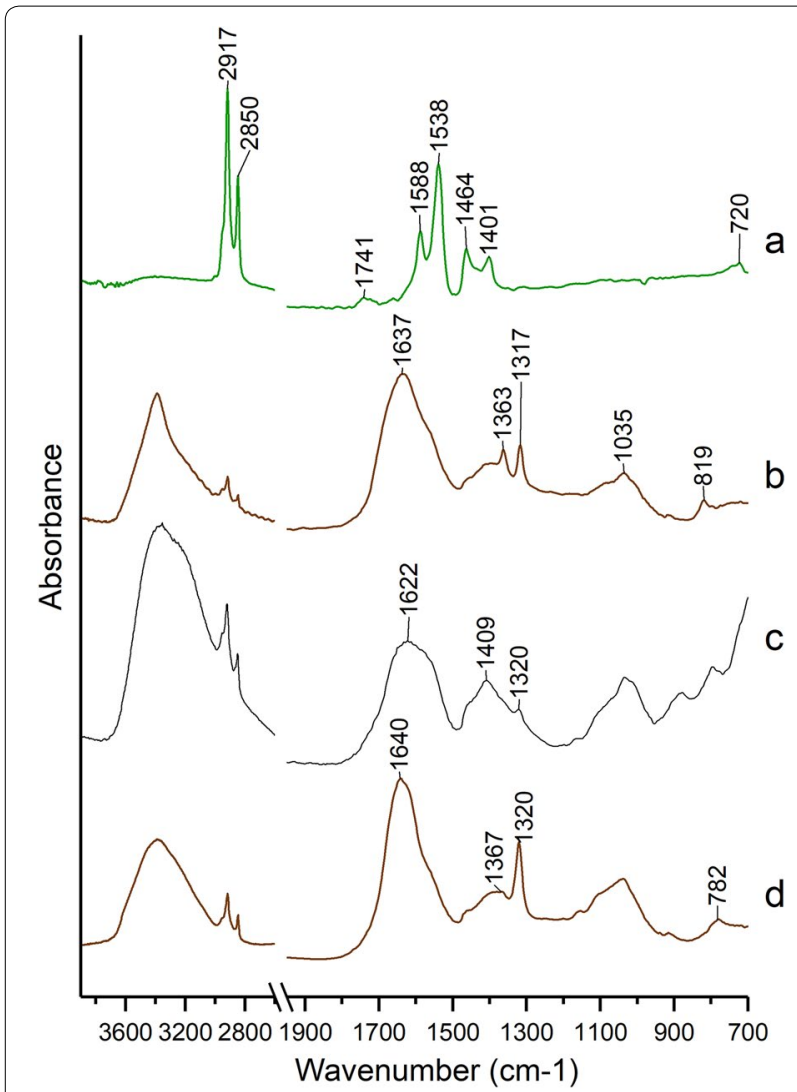

Fig. 8 FTIR spectra of the brown outlines: a Aye — green globule, b Aye-brown matrix surrounding green globule, c Mya —light brown outline and d Mya — dark brown outline

thought that the haze surrounding the remaining paint fragments could offer physical grip to adhere to the paint remnants. The extra tenacity of the haze's adherence to the paint was demonstrated by the difficulty to separate them during the sampling process. Considering that the inorganic zinc salts detected are water-insoluble, they can act as a barrier to moisture and slow down the corrosion of zinc. Taking into account of above reasons, the conservation decision was to leave the corrosion "as it is" until better treatment methods are available in the future. The primary concern for display and storage is to arrest the corrosion of zinc and preserve the current condition by keeping the paintings at a suitably low $\mathrm{RH}$ environment. In this case, a RH of $55-60 \%$ was suggested, considering that risk of mould growth is controlled below $60 \%$ and corrosion of zinc initiates above $70 \%$ [34].

\section{Conclusions}

The whitish haze and darkening of brown outlines presented on the Burmese paintings enabled an investigation of different degradation patterns of oil paint on zinc support. A part of the study also revealed the materials and artists' techniques used on these "Royal Family Portrait" paintings, an important collection in Burmese art. The UVF examination revealed the dating on Aye's painting to 1918 and on Mya's painting, the peculiar brushstrokes of the figures' bodies showed later retouching.

Both paintings used a similar pigment palette of lead white, Prussian blue and chrome yellow. The use of metallic particles, in this case aluminum for the embellishments on the clothing and brass in the brown outlines to highlight the metallic features, seemed to be a traditional technique to render luminosity. The use of brass paint, however, had inadvertently caused the formation of greenish globules of zinc and copper stearate or palmitate, dulling the brown outlines in Aye's painting. Metal oxalates, likely an oxidative degradation product of organic binder, also contributed to the darkening of the brown outlines. Stearic or palmitic acids for the formation of greenish globules could be derived from additive in wax mixtures, or zinc stearate additive in early commercial oil paint. If the latter was true, it would imply that the dark brown outlines were applied later in the 1920s. Although brass was also used in the brown outlines of Mya's painting and zinc carboxylates were detected, no green globule was observed. This result suggests that the brass paint applied by Mya was different from Aye's, without the presence of stearate or palmitic additive.

The whitish haze in the paintings was also investigated. Micro-analysis of the haze showed that the haze not only enveloped the paint surface (identified as mould or zinc carboxylates with wax), but also surrounded the paint islands (identified as zinc oxalates, zinc stearates or palmitates and carboxylates). In the latter, stable zinc oxalates attached to the zinc probably enhanced the paint's grip to the support. The layer beneath the paint (possibly ground) at the paint-metal interface was analysed as barium sulphate, zinc carboxylates and mineral wax. Wax was likely used as a hydrophobic coating to prepare the zinc support prior to paint application or as a wax varnish.

While the whitish haze can be distracting, removing the whitish haze would risk disrupting the paint's stability and causing loss of more paint. The zinc salts identified on zinc in areas of paint loss are water-insoluble and could protect the zinc support from further corrosion. With these considerations in mind, the whitish haze was considered stable and shall be left in situ.

\section{Method}

\section{Digital microscope}

Areas of the paintings were examined with a Keyence VHX-6000 digital microscope equipped with a white light source (LED lamp), high speed camera with $20 \times-$ $200 \times$ zoom lens or $100 \times-1000 \times$ zoom lens mounted 
onto a portable stand with horizontal arm with automated motor along $Z$-axis. Polished cross-section of the green globules, prepared with a polishing holder and micromesh of successive grades of $1200 \times$ to 12,000 grit, was examined using $100 \times-1000 \times$ zoom lens mounted onto a benchtop automated stage.

\section{Fourier transform infrared (FTIR) microscopy}

Micro-amounts of powder samples taken from the paintings were compressed in half diamond cells prior to analysis in transmission mode with the Agilent Cary $660 / 670$ spectrometer coupled to a microscope equipped with a single point MCT detector. The FTIR spectra were acquired at $4 \mathrm{~cm}^{-1}$, with 16-64 accumulations.

\section{Scanning electron microscope with energy dispersive spectroscopy (SEM-EDS)}

All samples (powdered paint samples and cross-section) were mounted on high purity carbon tapes and examined with a Hitachi SU5000 SEM coupled to a Bruker EDS at partial vacuum of about $60 \mathrm{~Pa}$ using back scattering detector at an accelerating voltage of $20 \mathrm{kV}$.

\section{Abbreviations \\ FTIR: Fourier transform infrared; SEM-EDS: scanning electron microscope- energy dispersive spectroscopy; UVF: ultraviolet fluorescence.}

\section{Acknowledgements}

The author gratefully acknowledges Filzah Mohd Amir, assistant conservator (paintings)/Heritage Conservation Centre and Maria del Mar Cusso Solano, conservator (paintings)/National Gallery Singapore, for the photography of paintings, discussions on the conservation aspects, and providing valuable feedback to this paper. Special thanks to Lisa Horikawa, Senior Curator of the National Gallery Singapore, for providing the historical information aspect of Burmese paintings.

\section{Authors' contributions}

LC conducted the examination of paintings, sampling, analyses, interpretation of datasets and writing of manuscript. The author read and approved the final manuscript

\section{Funding}

Not applicable.

\section{Availability of data and materials}

The datasets used and/or analysed during the current study are available from the author on request.

\section{Competing interests}

The author declares that he has no competing interests.

Received: 4 April 2019 Accepted: 22 June 2019

Published online: 04 July 2019

\section{References}

1. Summer J. Paintings on copper supports. 2018. http://www.conservati on-wiki.com/wiki/Paintings_on_Copper_Supports. Accessed 2019.

2. Pavlopoulou L-C, Watkinson D. The degradation of oil painted copper surfaces. Stud Conserv. 2006;51(sup1):55-65.
3. Veiga AR. Oil painting on tinplate by Francisco José Resende. Techniques, materials and degradation of three nineteenth century paintings. In: CeROArt. Conservation, exposition, Restauration d'Objets d'Art. Association CeROArt asbl. 2010.

4. Zaccaron S, Grespan C, Ganzerla R. Characterization of pigments on paintings on copper plate. A case study: the copy of La sepoltura di Cristo by Federico Barocci. Sci. Ca'Foscari. 2013.

5. Oliveira ML, Carlyle L, Fragoso S, Pombo Cardoso I, Coroado J. Investigations into paint delamination and consolidation of an oil painting on copper. In: Paintings on copper and other metal plates: production, degradation and conservation issues $=$ La pintura sobre cobre y otras planchas metalicas: produccion, degradacion y conservacion 2015. pp. 169-180

6. Horovitz I. Paintings on copper supports: techniques, deterioration and conservation. Conservator. 1986;10(1):44-8.

7. Thistlewood J, Northover P. Corrosion analysis and treatment of two paintings on zinc supports by Frederick Preedy. J Inst Conserv. 2009;32(2):137-48.

8. Selwyn L. Metals and corrosion: a handbook for the conservation professional. 2004. pp.149-155

9. Osmond G, Ebert B, Drennan J. Zinc oxide-centred deterioration in 20th century Vietnamese paintings by Nguyễ Trọng Kiệm (1933-1991). AICCM Bull. 2013;34(1):4-14.

10. Maor Y, Murray A. Delamination of oil paints on acrylic grounds. In: MRS Proceedings. 2007.

11. Van Loon A, Hoppe R, Keune K, Hermans JJ, Diependaal H, Bisschoff M, Thoury M, Van Der Snickt G. Paint delamination as a result of zinc soap formation in an early mondrian painting. In: Casadio F, editor. Metal soaps in art: conservation and research. Cham: Springer; 2019. p. 359-73.

12. Rogala D, Lake S, Maines C, Mecklenburg M. Condition problems related to zinc oxide underlayers: examination of selected abstract expressionist paintings from the collection of the Hirshhorn museum and sculpture garden, Smithsonian Institution. J Am Inst Conserv. 2010;49(2):96-113.

13. Ranard A. Burmese painting: a linear and lateral history. Chiang Mai: Silkworm Press; 2009.

14. Naing M. The beginnings of burmese painting. Trans Paw Htin Forward. 1979;17(11):14-9.

15. Naing M. The Royal Artist Saya Chone. (In Burmese) Trans. In :Ye Myint T. Rangoon: Sarpay Beikman: Commissioned by Ranard. 1980.

16. Keck SL. British Burma in the new century, 1895-1918. Cham: Springer; 2015.

17. Edwards HG, Hassan NFN, Middleton PS. Anatase-a pigment in ancient artwork or a modern usurper? Anal Bioanal Chem. 2006;384(6):1356-65.

18. Rogge $C E$, Arslanoglu J. Distinguishing manufacturing practices for titanium white pigments: new Raman markers for dating commercial oil-based paints. Stud Conserv. 2016;61(sup2):324-6.

19. Horikawa L. Personal Communication with Curator on the Burmese paintings on zinc support. Singapore: National Gallery of Singapore; 2018.

20. Tumosa CS. A brief history of aluminum stearate as a component of paint WAAC newsletter. 2001;23(3). https://cool.conservation-us.org/waac/wn/ wn23/wn23-3/wn23-304.html

21. Joseph E, Cario S, Simon A, Wörle M, Mazzeo R, Junier P, Job D. Protection of metal artifacts with the formation of metal-oxalates complexes by Beauveria bassiana. Front Microbiol. 2012;2:270.

22. Helwig K, Poulin J, Corbeil M-C, Moffatt E, Duguay D. Conservation issues in several twentieth-century canadian oil paintings: the role of zinc carboxylate reaction products. In: van den Berg JK, editor. Issues in contemporary oil paint. Cham: Springer; 2014. p. 167-84.

23. Robinet $L$, Corbeil M-C. The characterization of metal soaps. Stud Conserv. 2003;48(1):23-40.

24. Otero V, Sanches D, Montagner C, Vilarigues M, Carlyle L, Lopes JA, Melo MJ. Characterisation of metal carboxylates by Raman and infrared spectroscopy in works of art. J Raman Spectrosc. 2014;45(11-12):1197-206.

25. Gramtorp D, Botfeldt K, Glastrup J, Simonsen KP. Investigation and conservation of Anne Marie Carl-Nielsen's wax models. Stud Conserv. 2015;60(2):97-106.

26. Ferreira ES, Gros D, Wyss K, Scherrer NC, Zumbühl S, Marone F. Faded shine The degradation of brass powder in two nineteenth century paintings. Herit Sci. 2015;3(1):24.

27. Nevin A, Melia JL, Osticioli I, Gautier G, Colombini MP. The identification of copper oxalates in a 16th century Cypriot exterior wall painting using 
micro FTIR, micro Raman spectroscopy and gas chromatography-mass spectrometry. J Cult Herit. 2008;9(2):154-61.

28. Monte M. Oxalate film formation on marble specimens caused by fungus. J Cult Herit. 2003;4(3):255-8.

29. Rosado T, Gil M, Mirão J, Candeias A, Caldeira AT. Oxalate biofilm formation in mural paintings due to microorganisms - a comprehensive study. Int Biodeterior Biodegrad. 2013;85:1-7.

30. Cezar T. Calcium oxalate: a surface treatment for limestone. J Conserv Mus Stud. 1998:4:6-10.

31. Poli T, Piccirillo A, Zoccali A, Conti C, Nervo M, Chiantore O. The role of zinc white pigment on the degradation of shellac resin in artworks. Polym Degrad Stab. 2014;102:138-44.

32. Sotiropoulou S, Papliaka ZE, Vaccari L. Micro FTIR imaging for the investigation of deteriorated organic binders in wall painting stratigraphies of different techniques and periods. Microchem J. 2016;124:559-67.
33. Martinelango PK, Dasgupta PK, Al-Horr RS. Atmospheric production of oxalic acid/oxalate and nitric acid/nitrate in the Tampa Bay airshed: parallel pathways. Atmos Environ. 2007:41(20):4258-69.

34. Stoner JH, Rushfield R. Conservation of easel paintings. New York: Taylor \& Francis; 2013

\section{Publisher's Note}

Springer Nature remains neutral with regard to jurisdictional claims in published maps and institutional affiliations.

\section{Submit your manuscript to a SpringerOpen ${ }^{\odot}$ journal and benefit from:}

- Convenient online submission

- Rigorous peer review

- Open access: articles freely available online

- High visibility within the field

- Retaining the copyright to your article

Submit your next manuscript at $\boldsymbol{\nabla}$ springeropen.com 